\title{
PERCEPÇAO DOS ESTUDANTES SOBRE O PROCESSO DE ENSINO E SUA RELAÇÃO COM O PROJETO DO CURSO
}

\author{
Maria Lenir Stüpp ${ }^{1}$
}

Este trabalho trata da percepção de estudantes de ensino médio sobre o processo de ensino e de aprendizagem e sua relação com o Projeto Pedagógico do Curso. Trata-se do relato de uma experiência relacionada a atividade do Conselho de Classe que teve como objetivo desencadear uma dinâmica de colegiado em que o objeto do trabalho do Conselho fosse 0 processo e não o produto. Justifica esta opção o fato de que, historicamente, 0 foco da atenção nos Conselhos de Classe estava centrado em questões comportamentais e de indisciplina, sem que houvesse qualquer encaminhamento para a superação das dificuldades de aprendizagem, frequentemente de baixo rendimento $e$, menos ainda, uma análise sobre $O$ processo pedagógico em sua multiplicidade de fatores. A atividade revelou-se um passo importante e fundamental para a necessária quebra do velho paradigma com relação a lógica de realização das reuniões de Conselho de Classe, além de ter oportunizado perceber a distância existente entre o que preconiza o projeto de curso e o que, efetivamente, de seus princípios está presente na materialização dos componentes curriculares no cotidiano das salas de aula. Pela relevância das informações que a atividade propiciou, decidiu-se por publicizá-la na forma deste trabalho, para o qual se buscou incorporar algumas reflexões e contribuições teóricas enquanto proposição de estudo, sem, contudo, tecer uma discussão acurada nela articulada, em função das especificidades e circunstâncias objetivas.

Sendo assim, o presente objeto é derivado do Conselho de Classe para o qual é realizado o diagnóstico sobre o processo de ensino e de aprendizagem. As informações foram obtidas através de avaliação diagnóstica realizada com os estudantes para subsidiar o Conselho, como também foram tomados excertos da concepção do curso para estabelecer relação entre os

\footnotetext{
${ }^{1}$ Instituto Federal Catarinense Campus Rio do Sul (lenir@ifc-riodosul.edu.br)
} 
fundamentos do projeto de curso, a dinâmica de trabalho docente e a percepção dos estudantes sobre este processo.

A sondagem sobre o processo de ensino e de aprendizagem realizado com os estudantes, além de costumeiro subsídio para o conselho de classe, foi motivada pelos recorrentes questionamentos dos estudantes com relação ao curso e sua rotina no que diz respeito a dinâmica das aulas, bem como das motivações apresentadas por estudantes para desistirem do curso. Diante das informações levantadas, buscou-se no Projeto Pedagógico de Curso os fundamentos e pressupostos do referido curso para identificar qual a relação destes pressupostos com a fala dos estudantes e, assim, subsidiar a reflexão no Conselho de Classe.

Para a realização da avaliação diagnóstica, foi sugerido aos estudantes que escrevessem uma carta para os professores sobre suas expectativas em relação ao curso e de como estavam acompanhando o processo de ensino. Sobre sua percepção e o como estavam se sentindo em relação a rotina das aulas e dos estudos desde o primeiro trimestre, e que apresentassem sugestões para os professores de como gostariam que fossem as aulas para melhorar a aprendizagem e os seus estudos diários.

O primeiro momento da atividade do Conselho consistiu em rememorar os princípios filosóficos e pedagógicos constantes do Projeto Pedagógico do Curso onde trata da Concepção do Curso, aos quais foram acrescidas perguntas concernentes ao compromisso com a ação no processo de ensino e sua correspondente sintonia com os fundamentos.

"A proposta pedagógica é orientada em uma perspectiva interdisciplinar e transdisciplinar, superando a fragmentação entre os saberes técnicos e incentivando saberes voltados para os valores e relações humanas". (PPC p.17, grifo meu).

Pergunta: De que forma tenho trabalhado na perspectiva interdisciplinar e transdisciplinar? Onde percebo a superação da fragmentação dos saberes em minha prática?

"Dentro dos princípios filosóficos e pedagógicos, diversos pressupostos são contemplados, tais como o ético-político, antropológicosocial, epistemológico e didático-pedagógico". (PPC p.17, grifo meu). 
Pergunta: Onde e como se evidencia que os pressupostos ético políticos, antropológico-social e epistemológico foram contemplados em meu trabalho docente?

Baseado nos princípios e fins da Educação Nacional, a escola tem por finalidade o desenvolvimento do educando, seu preparo para 0 exercício da cidadania e sua qualificação para 0 trabalho proporcionando conhecimentos formais e de formação humanista, direcionado para a vivência solidária, estimulando ainda 0 desenvolvimento do senso crítico para interagir no mundo contemporâneo. (PPC p.17).

[...] devemos educar nossos alunos preparando-os para que se constituam em indivíduos competentes, criativos, éticos, participativos, autênticos e que cultivem os valores de vida. (PPC p.18).

[...] buscamos uma nova sociedade onde homens e mulheres sejam co-responsáveis e co-participantes dos fatos, valorizando o "ser" sobre o "ter", cultivando o respeito, a valorização da vida, os limites da natureza e os princípios de igualdade, fraternidade e justiça. (PPC p.18, grifo meu).

Pergunta: Qual a especificidade de minha prática que mais contribui para "buscarmos uma nova sociedade onde homens e mulheres sejam corresponsáveis e coparticipantes dos fatos, valorizando o "ser" sobre o "ter", cultivando o respeito, a valorização da vida, os limites da natureza e os princípios de igualdade, fraternidade e justiça"?

Para esta concepção de sociedade entendemos que o educando deva ser atuante, responsável e consciente dos seus deveres e dos seus direitos enquanto cidadão, participativo, crítico, empreendedor e que assuma seu papel como sujeito e agente de mudanças na sociedade. Na escola busca sua qualificação profissional, novos conhecimentos e 0 significado para aquilo que executa, desenvolvendo habilidades e competências para atuar no mundo do trabalho. (PPC, p.18). (grifos meus).

Ao interagir com o conhecimento o ser humano se transforma, constrói significados a partir das informações contextualizadas, amplia seus conhecimentos, lida com conceitos científicos hierarquicamente relacionados o que possibilita novas formas de pensamento, inserção e atuação em seu meio. A proposta de ensino é um canal de comunicação entre o conhecimento e a investigação entre professor e aluno, visando à construção de conceitos e significados necessários para o desenvolvimento de uma atitude interdisciplinar, criando assim novas formas de ensinar e aprender. (PPC, p.18, grifos meus).

Pergunta: De que forma organizei minhas aulas para que "ao
interagir com o conhecimento o ser humano se transforma, constrói significados a partir das informações contextualizadas"?

A ação pedagógica é caracterizada por uma metodologia dinâmica, que integra reflexão-ação-interação-construção, através da organização do pensamento numa relação dialógica que resulta no desenvolvimento de habilidades, na construção do conhecimento e 
na participação consciente, alegre e comprometida de educandos e educadores. (PPC. p.19, grifos meus).

Esse processo dinâmico apresenta-se em forma de atividades interdisciplinares, despertando a curiosidade e o gosto pelo conhecimento através da pesquisa [...], e TUDO o que permite a inserção do aluno no processo de (re)construção do conhecimento. Com clareza de objetivos, estratégias, recursos e metodologias, desafia-se $o$ aluno a aprender a aprender, aprender a ser, aprender a conviver e aprender a fazer, pois o processo de aprender é permanente. (PPC. p.19, grifos meus).

Pergunta: De que forma, e em que medida, eu tenho correspondido e me comprometido com esses pressupostos e princípios educacionais?

Articulado ao olhar sobre os princípios do curso acima referidos e a reflexão sobre a sintonia destes com o ato de ensinar seguiu-se a exposição da percepção dos estudantes, sendo que, para este trabalho foram selecionadas apenas algumas percepções a fim de preservar os sujeitos em questão.

[...] Eu me sinto um lixo, pois, aprendendo ou não, o professor irá ter o seu salário, mesmo não dando aula direito, [...] e dizendo aos alunos para dar aula;

Nas apresentações erradas feitas em sala, o professor não corrigiu... Espero que daqui em diante o professor intervenha;

Tem professor que não sabe ensinar;

A turma precisa fazer mais silêncio porque o professor não consegue nem fazer a chamada;

Professor não faz nada, não planeja nada, não explica e passa prova sem avisar. Como ele mesmo diz: 'façam, o que quiserem, no fim do mês o meu salário está garantido'. Ele não tá nem aí para nada;

Aulas [...] chatas, inúteis - faz uma anotação e depois fica enchendo linguiça para a próxima aula. Se resume em anotar e mandar refazêla - seria uma boa ideia explicar a atividade antes de começarmos a fazer outra coisa. Repetição das mesmas coisas sem ter melhor explicação;

Temos que fazer exercícios e atividades sem saber por que nem para que serve;

Sempre tive facilidade de lembrar, mas escrever, para mim é uma grande tortura, me atrapalho, fico agoniado;

Em todas as aulas eu me sinto perdido e que estou fazendo algo sem propósito [...] ele mesmo admitiu que não olha o que a gente enviou;

Acho que temos muitos professores que são cabeça fechada e que não aceitam mudar seus conceitos sobre as coisas que necessitam mudar;

[...] Não sabe dar aula. Temos que aprender sozinhos, além de termos uma nota ridícula $[\ldots]$;

Queria pedir para professor não demorar tanto para começar a aula porque é a aula que mais gosto e não gosto de perder tempo;

Professor que não tem vontade nenhuma de dar aula, não orienta 0 aluno quando há alguma dúvida, tem que ser urgentemente substituído;

Que professor planejasse uma aula e desse uma aula pois [...] e fica sentado olhando. Está pouco preocupado com nós, bate de frente com alunos, é IGNORANTE. 
Os exercícios que o professor passa, na maioria são difíceis e não é como no slide. Poucos conseguem fazer e daí vão mal na prova.

Acho que sua forma de chamar a atenção dos alunos onde você algumas vezes tira sarro da cara do aluno acaba falhando, pois isso vai apenas criar um ressentimento não de culpa, mas de ódio [...];

Gostaria que antes de fazer prova, tivesse exercícios e corrigisse e que fossem aos poucos, não tudo de uma vez só e também que parasse de usar os alunos como exemplo e com [...] difíceis e caçoasse dos alunos;

Professor [...] que parece sargento dando ordens e acaba não ensinando, que culpa um único aluno por causa da bagunça;

Aula chata baseia-se em professor ficar falando e não passar atividade, assim dá sono, preguiça e torna a matéria que é chata mais chata ainda. Professor deveria passar mais exercícios e falar menos, ou seja, fazer uma aula mais participativa, pois são $55 \mathrm{~min}$ com alunos com sono. Deveria de passar mais exercícios e cobrá-los na outra aula e depois corrigi-los. (grifos meus).

Conforme o exposto sobre os aspectos que constituíram a reunião de Conselho, têm-se, de um lado, os princípios para o processo educativo preconizados no projeto de curso e de outro, a percepção dos estudantes sobre o respectivo processo em sua dinâmica cotidiana. Tomando-se os referenciais e as falas dos estudantes, pergunta-se: é possível identificar sintonia ou relação entre o que preconiza o projeto pedagógico do curso e sua dinâmica explicitada no ato de ensinar e, ao mesmo tempo, em sua expressão vivida pelos atores beneficiários - os estudantes? É possível uma relação de sentido entre o preconizado no Projeto do Curso e a realidade descrita pelos estudantes?

O que ficou caracterizado na afirmação dos estudantes corrobora com um processo de ensino mecânico, uma vez que não conseguem perceber sentido no que fazem, ao explicitarem de forma evidente expressões como, "aulas inúteis", "fica enchendo linguiça para a próxima aula", "temos que fazer exercícios e atividades sem saber por que nem para que serve", "repetição", "me sinto perdido e que estou fazendo algo sem propósito". Percepções que se mostram antagônicas a orientação do projeto em epígrafe, para o qual "o ensino será desenvolvido com base nos princípios da interdisciplinaridade, da pesquisa", de forma dinâmica e desafiadora para os estudantes, a fim de propiciar motivação para despertar sua curiosidade científica.

Pelo conteúdo e seu sentido expresso nas falas dos estudantes não foi possível identificar que, no seu cotidiano haja uma relação dialógica no que diz respeito ao ensinar e ao aprender. 
As contradições entre as falas e o que está proposto no projeto do curso para o ensino evidenciam-se na afirmação de que "a proposta de ensino é um canal de comunicação entre o conhecimento e a investigação entre professor e aluno, visando à construção de conceitos e significados necessários para o desenvolvimento de uma atitude interdisciplinar, criando assim novas formas de ensinar e aprender" (PPC - grifos meus).

Constata-se nas falas dos estudantes um apelo para que os professores desenvolvam uma prática de ensino na qual se sintam respeitados. Manifestam o desejo de aprender. Pedem aos professores para que desenvolvam os conteúdos de forma que possam compreender e desenvolver as atividades de estudo. "Peço para separar suas aulas em tópicos"; "professor precisa explicar o assunto"; "não falar tanto, pois são 55 minutos de alunos com sono"; "falar menos, ou seja, fazer uma aula mais participativa".

Sugerem que o tempo das aulas não seja desperdiçado, "não demorar tanto para começar a aula, não gosto de perder tempo, é aula que gosto". Sugerem formas de que o professor poderia se apropriar e trabalhar para que pudessem melhor aprender. "Gostaria os exercícios com um tempo de separação, pois percebo que quando o professor joga 7, 12 ou mais exercícios ao mesmo tempo, a turma não entende tão bem o assunto"; "[...] pode acontecer de o professor recusar, mas queria pedir para o senhor separar suas aulas em 'tópicos' e realizar trabalhos sobre eles [...]”; "[...] um pouco 'maçante' [...] já estão bem melhores, mas acho que deveria dar mais trabalhos para nós exercitarmos o nosso conhecimento próprio [...]. Desculpe se de alguma forma ofendi vocês, desde já agradeço pela atenção".

Sugerem o diálogo, "acho que deveria haver sempre que possível uma conversa entre o aluno e o professor ao particular para saber o que o professor sente do aluno e o aluno do professor, como já foi feito com alguns professores". Uma demonstração de maturidade e respeito para com seus professores.

Embora no projeto conste que,

ao interagir com o conhecimento o ser humano se transforma, constrói significados a partir das informações contextualizadas, amplia seus conhecimentos, lida com conceitos científicos hierarquicamente relacionados o que possibilita novas formas de pensamento, inserção e atuação em seu meio, (p.18) 
a descrição sobre a realidade vivida e experienciada pelos estudantes com relação a dinâmica em sala de aula e de sua relação com o aprendizado denota pouca ou quase nenhuma relação com o que está proposto no projeto do curso, notadamente quando afirma, "buscamos uma nova sociedade onde homens e mulheres sejam corresponsáveis e coparticipantes dos fatos, valorizando o 'ser' sobre o 'ter', cultivando o respeito, a valorização da vida, os limites da natureza e os princípios de igualdade, fraternidade e justiça". (PPC - grifos meus).

Corroborado ainda, nas falas abaixo, a discrepância entre 0 pretendido e o realizado com relação ao que sentem, experimentam, compreendem e, consequentemente, se apropriam na rotina escolar.

Professor que parece sargento dando ordens e acaba não ensinando,
que culpa um único aluno por causa da bagunça.
Acho que sua forma de chamar a atenção dos alunos onde você
algumas vezes tira sarro da cara do aluno [...].
Não marcar os alunos, não ridicularizar os alunos, parar com as
piadas sem graça.
Nos tratando como um objeto, uma coisa qualquer. Fazemos
perguntas e você responde grosso como se estivéssemos
perguntando uma coisa que já sabíamos.

Diante do exposto, somos instigados a inquirir sobre o que há de real e de concreto no objeto em tela, nomeadamente as falas dos estudantes. O que nelas está oculto? O que há de apenas aparente? Qual é o seu núcleo central? Quais seus nexos e redes causais? Para tentar entender estas indagações, outros questionamentos são necessários, como: qual a trilha a ser percorrida para desvendar o fenômeno descrito e conhecê-lo em sua gênese, seus nexos e suas redes causais?

Recorremos a MORAES (2000), cujos estudos e produções nos apontam para os fundamentos que possibilitam clarear, ao menos em parte, os questionamentos e, portanto, desvelar parte do fenômeno.

Em seu artigo ${ }^{2}$ sobre " $A$ história como horizonte ontológico" trata sobre o pensamento dialético e a ontologia a partir das obras de Marx e Lukács para explicitar sobre o caminho metodológico pelo qual elucidou seu objeto de estudo. Apresenta a dialética como caminho metodológico a ser percorrido

${ }^{2}$ MORAES, Maria Célia Marcondes de. A dupla problemática do objeto da História: ontológica e metodológica. Florianópolis: UFSC. Centro de Ciências da Educação. Núcleo de Publicações, 2000. (Teses NUP:4) 
para conhecer o fenômeno em sua essência, pois o pensamento dialético é o processo de concretização que procede do todo para as partes e das partes para o todo, dos fenômenos para a essência e da essência para os fenômenos, da totalidade para as contradições e das contradições para a totalidade. $\mathrm{Na}$ dialética parte-se das determinações simples, imediatas, para, então, avançar para o conhecimento da totalidade concreta enquanto reprodução da realidade no pensamento. Com este itinerário complexo pode-se desvendar o fenômeno em sua concretude, "conhecendo-se suas múltiplas determinações". "A dialética apresenta o real como totalidade e indica que as categorias são postas pelo movimento contraditório do real" (p.24), elas "são formas de ser, são determinações da existência e reproduzem um movimento que se dá, primeiramente, no próprio objeto, em suas relações e vinculações, sem cujo conhecimento os homens não poderiam se orientar em seu mundo circundante" (p.24). O método dialético exige que o conhecimento apreenda as determinações de conteúdo no próprio movimento pelo qual elas se desdobram, estabelecendo a conexão necessária e imanente entre elas. (p.36).

Em LUKÁCS ${ }^{3}$, a dialética é a lógica do movimento, das contradições, da evolução, da mudança e, portanto, considera as coisas e conceitos no seu encadeamento e nas suas relações mútuas, em ação recíproca. A dialética expressa um modo de compreender o mundo como realidade concreta com suas "múltiplas determinações". Esclarece que a Dialética e a Ontologia do Ser Social fundamentam o método dialético, e este, esclarece sobre a forma de concepção de realidade ou de mundo segundo esse fundamento. O método dialético compreende o caminho teórico que expressa a concepção de mundo como totalidade, a qual não é um atributo da realidade, mas a própria concepção de realidade histórica. Totalidade, enquanto categoria explicativa da relação das partes entre si, e como tal, "portadora do princípio revolucionário de ciência". A apreensão da realidade como um todo processual - se dá através da elucidação de seus determinantes e de seus nexos constitutivos, o que ocorre através da mediação das categorias analíticas para se chegar a uma compreensão ontológica sobre ela.

\footnotetext{
${ }^{3}$ LUKÁCS, Gyorgy. Para uma ontologia do ser social I. São Paulo: Boitempo, 2012; LUKÁCS, Gyorgy. Para uma ontologia do ser social II. São Paulo: Boitempo, 2013.
} 
Por isso, "só a investigação ontológico-genética da essência pode trazer à tona a verdade sobre o mundo fenomênico" (Lukács, 2013, p.380), e "todo fato deve ser visto como parte de um complexo dinâmico em interação com outros complexos, como algo que é determinado, tanto interna como externamente, por múltiplas leis." (Lukács 2013, p. 388).

O processo dinâmico da realidade é constituído pela própria essencialidade da realidade. E o que dá dinamismo a essa totalidade é o sistema de contradição e antagonismos, os quais precisam ser apreendidos em suas particularidades que se constituem em suas especificidades concretas nos fenômenos. Além das particularidades que se caracterizam pelo sistema de contradição e antagonismo, eles estão num processo de relação constante. "Só a gênese pode expor as formas ontologicamente concretas, as tendências dos movimentos, as estruturas etc. de uma determinada forma de ser em seu ser-propriamente-assim concreto e, por essa via, avançar até as suas legalidades específicas" (Lukács, 2013, p. 458), porque "na vida cotidiana os fenômenos frequentemente ocultam a essência do seu próprio ser, ao invés de iluminá-la". (Lukács, 2012, p.294).

Os breves apontamentos sobre o caminho metodológico a ser trilhado para se chegar ao conhecimento de dado fenômeno/objeto e trazer à luz a sua essência fenomênica, sua gênese, suas redes e seus nexos causais com o aporte dos autores escolhidos, é de singular relevância. Com eles temse a possibilidade de investigar em que medida o curso, o currículo, a profissionalização docente e a estrutura educacional com seu arcabouço técnico-ideológico-instrumental constituem relações imanentes e identitárias com os efeitos de seus processos explicitados pelos estudantes, registrando que "essência e fenômeno constituem uma unidade indivisível em sua imediatidade" (Lukács, 2013, p. 493).

\section{CONSIDERAÇÕES FINAIS}

Tendo em vista que o presente objeto não foi discutido segundo os fundamentos e pressupostos de análise para fenômenos ou fatos socialmente determinados e historicamente situados para elucidar sua gênese, seus nexos e suas redes causais de modo a conhecer a sua essência fenomênica 
conforme acima indicado, mas tão somente os refere como a opção teórica pela qual compreende ser a base capaz de explicitar em sua multiplicidade 0 fenômeno em tela, retoma-se a questão inicial, a qual se propôs em apresentar a percepção dos estudantes sobre a inter-relação que se estabelece no processo de ensino e de aprendizagem, expressa nas suas falas.

Tal opção se deve ao fato de se constituir como proposição para o estudo, e de outro, devido às especificidades do presente trabalho.

Finaliza-se, então, na expectativa de que a contribuição trazida pela percepção dos estudantes sobre a rotina da sala de aula possa motivar os educadores a engendrar um "outro mundo possível" na sua relação com o conhecimento, uma vez que se é levado a presumir que "outras práticas pedagógicas são possíveis". Uma delas teve como efeito o entendimento e a percepção de relações estabelecidas em sala de aula e, com ela conclui-se o presente texto.

\begin{abstract}
Saudações, Prof[...], estou escrevendo esta carta [...]. Sei que a maioria dos alunos está escrevendo tudo o que não gostam [...]; talvez eu devesse fazer o mesmo, mas resolvi escrever esta carta por outro motivo. Só queria dizer que amo as suas aulas. Nunca odiei matéria alguma na escola, mas você me fez, pela primeira vez, gostar realmente de uma aula que não seja das exatas. Alguns alunos não gostam de você, mas entendo, todo mundo gosta de algumas pessoas e nem tanto de outras. Mas eu achei você incrível. Alguns até falam que você passa tempo demais contando histórias e ainda os assusta quando fala alto [...]. A maioria acha engraçado. E eu acho incrível. Você fala, fala e fala, e quando todo mundo está se perguntando o porquê de ter nos contado isto, BUM! A história tem um desfecho, uma moral, e eu só consigo pensar: "Caramba!", porque no fim a historia tem tudo a ver com o que nós estamos estudando. Sério, professor, suas aulas são incríveis, sua didática é incrível; VOCÊ é incrível. Obrigada por tornar as aulas mais divertidas e fáceis de aprender. Putz, acabou a aula, tenho que ir. Adoro você! Abraço!
\end{abstract}

\title{
REFERÊNCIAS
}

IFC - Instituto Federal de Educação, Ciência e Tecnologia Catarinense Campus Rio do Sul. Projeto Pedagógico do Curso de Educação Profissional Técnica de Nível Médio. Julho/2010.

LUKÁCS, Gyorgy. Os princípios ontológicos fundamentais de Marx. In: LUKÁCS, Gyorgy. Para uma ontologia do ser social I. São Paulo: Boitempo, 2012. 
LUKÁCS, Gyorgy. Para uma ontologia do ser social II. São Paulo: Boitempo, 2013.

MEC - Um novo modelo em educação profissional e tecnológica: concepção e diretrizes, 2010. Disponível em: $<$ http://portal.mec.gov.br/dmdocuments/livreto institutos.pdf.> Acesso em: 09 out. 2015.

MORAES, Maria Célia Marcondes de. A dupla problemática do objeto da História: ontológica e metodológica. Florianópolis: UFSC. Centro de Ciências da Educação. Núcleo de Publicações, 2000. (Teses NUP:4)

MORAES, Maria Célia Marcondes de. 0 renovado conservadorismo da agenda pós-moderna. Centro de Ciências da Educação da Universidade Federal de Santa Catarina - Florianópolis. Cadernos de Pesquisa, v. 34, n. 122, maio/ago. 2004. 